UDC 51-73+537.2 Вестник СПбГУ. Прикладная математика. Информатика... 2021. Т. 17. Вып. 2 MSC 35J05, 78A30

\title{
Mathematical modeling of triode system on the basis of field emitter with ellipsoid shape*
}

\section{N. V. Egorov, E. M. Vinogradova}

St. Petersburg State University, 7-9, Universitetskaya nab., St. Petersburg, 199034, Russian Federation

For citation: Egorov N. V., Vinogradova E. M. Mathematical modeling of triode system on the basis of field emitter with ellipsoid shape. Vestnik of Saint Petersburg University. Applied Mathematics. Computer Science. Control Processes, 2021, vol. 17, iss. 2, pp. 131-136. https://doi.org/10.21638/11701/spbu10.2021.203

In this paper the mathematical modeling of the triode emission axially symmetric system on the basis of field emitter is considered. Emitter is an ellipsoid of revolution, anode is a confocal ellipsoidal surface of revolution. Modulator is a part of the ellipsoidal surface of revolution, confocal with the cathode and anode surfaces. The boundary-value problem for the Laplace's equation in the prolate spheroidal coordinates with the boundary conditions of the first kind is solved. The variable separation method is applied to calculate the axisymmetrical electrostatic potential distribution. The potential distribution is represented as the Legendre functions expansion. The expansion coefficients are the solution of the system of linear equations. All geometrical dimensions of the system are the parameters of the problem.

Keywords: micro- and nanoelectronics, field emitter, field emission, mathematical modeling, electrostatic potential, boundary-value problem, Legendre functions.

1. Introduction. Field emitters are extensively used as electron sources of high current density for vacuum micro- and nanoelectronic devices [1-5]. This work is devoted to the mathematical modeling of an axially symmetric triode system on the basis of field emitter with ellipsoidal shape. The cathode's and anode's shapes are the confocal ellipsoidis of revolution. The modulator's shape is the part of the confocal ellipsoid of revolution (Figure). To calculate the axially symmetric electrostatic potential distribution the variable separation method in the prolate spheroidal coordinates $(\alpha, \beta)$ is used. In accordance with the theory of mathematical physics the boundary value problems with the mixed boundary conditions for the bounded domain can be reduced to the linear algebraic equations system with constant coefficients $[6,7]$.

2. Mathematical model. The problem parameters: $\alpha=\alpha_{1}(\beta \in[0, \pi])-$ cathode surface; $\alpha=\alpha_{3}(\beta \in[0, \pi])$ - anode surface; $\alpha=\alpha_{2}\left(\beta \in\left[\beta_{0}, \pi\right]\right)$ - modulator surface; $U(1 ;)=0$ - cathode boundary condition; $U\left(\alpha_{2}, \beta\right)=f(\beta),\left(\beta \in\left[\beta_{0}, \pi\right]\right)$ - modulator boundary condition; $U\left(\alpha_{3}, \beta\right)=0$ - anode boundary condition.

The electrostatic potential distribution $U(\alpha, \beta)$ is a solution of the boundary-value problem for the Laplace's equation:

$$
\frac{1}{c^{2}\left(\sin ^{2} \beta+\sinh ^{2} \alpha\right)}\left[\frac{\partial^{2} U}{\partial \alpha^{2}}+\operatorname{coth} \alpha \frac{\partial U}{\partial \alpha}+\frac{\partial^{2} U}{\partial \beta^{2}}+\cot \beta \frac{\partial U}{\partial \beta}\right]=0,
$$

* This work was supported by the Russian Foundation for Basic Research (project N 20-07-01086).

(C) St. Petersburg State University, 2021 


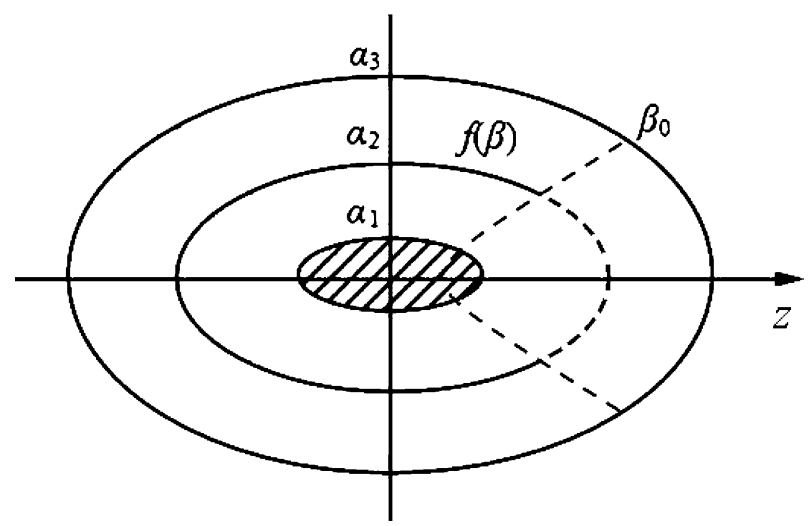

Figure. Schematic representation of the triode field emission system

and boundary conditions:

$$
\begin{cases}U\left(\alpha_{1}, \beta\right)=0, & \beta \in[0, \pi], \\ U\left(\alpha_{3}, \beta\right)=0, & \beta \in[0, \pi], \\ U\left(\alpha_{2}, \beta\right)=f(\beta), & \beta \in\left[\beta_{0}, \pi\right],\end{cases}
$$

where $c-$ focal radius.

3. Solution of the problem. To solve the boundary-value problem (1), (2) the internal area of the system can be divide into following subdomains:

(1) $-\left(\alpha \in\left[\alpha_{1}, \alpha_{2}\right], \quad \beta \in[0, \pi]\right)$;

(2) $-\left(\alpha \in\left[\alpha_{2}, \alpha_{3}\right], \quad \beta \in[0, \pi]\right)$;

Let

(3) $-\left(\alpha \in\left[\alpha_{1}, \alpha_{3}\right], \quad \beta \in\left[0, \beta_{0}\right]\right)$.

$$
U(\alpha, \beta)= \begin{cases}U_{1}(\alpha, \beta), & \alpha \in\left[\alpha_{1}, \alpha_{2}\right], \quad \beta \in[0, \pi], \\ U_{2}(\alpha, \beta), & \alpha \in\left[\alpha_{2}, \alpha_{3}\right], \quad \beta \in[0, \pi], \\ U_{3}(\alpha, \beta), & \alpha \in\left[\alpha_{1}, \alpha_{3}\right], \quad \beta \in\left[0, \beta_{0}\right] .\end{cases}
$$

Making use of the variable separation method for the (i)-th subdomain, the potential distribution $(3), U_{i}(\alpha, \beta)(i=1,2,3)$ accordingly, can be represented as [8-11]:

$$
\begin{aligned}
& U_{1}(\alpha, \beta)=\sum_{n=0}^{\infty} A_{n} P_{n}(\cos \beta) \frac{W_{n}\left(\alpha_{1}, \alpha\right)}{W_{n}\left(\alpha_{1}, \alpha_{2}\right)}, \\
& U_{2}(\alpha, \beta)=\sum_{n=0}^{\infty} A_{n} P_{n}(\cos \beta) \frac{W_{n}\left(\alpha, \alpha_{3}\right)}{W_{n}\left(\alpha_{2}, \alpha_{3}\right)}, \\
& U_{3}(\alpha, \beta)=\sum_{m=1}^{\infty} B_{m} \bar{W}_{-1 / 2+i \tau_{m}}\left(\alpha_{1}, \alpha\right) \frac{P_{-1 / 2+i \tau_{m}}(\cos \beta)}{P_{-1 / 2+i \tau_{m}}\left(\cos \beta_{0}\right)},
\end{aligned}
$$

where $[12-14]$ 


$$
\begin{gathered}
W_{n}(x, y)=P_{n}(\cosh x) Q_{n}(\cosh y)-P_{n}(\cosh y) Q_{n}(\cosh x), \\
\bar{W}_{-1 / 2+i \tau_{m}}(x, y)=P_{-1 / 2+i \tau_{m}}(\cosh x) Q_{-1 / 2+i \tau_{m}}(\cosh y)- \\
-P_{-1 / 2+i \tau_{m}}(\cosh y) Q_{-1 / 2+i \tau_{m}}(\cosh x)
\end{gathered}
$$

$P_{n}(\cos \beta)$ - Legendre polynomials; $P_{-1 / 2+i \tau_{m}}(\cos x)$ - conical functions; $P_{n}(\cosh x)$, $P_{-1 / 2+i \tau_{m}}(\cosh x)$ - Legendre functions of the first kinds; $Q_{n}(\cosh x), Q_{-1 / 2+i \tau_{m}}(\cosh x)-$ Legendre functions of the second kinds; $\tau_{m}$ - roots of a linear combination of Legendre functions of the first and second kind:

$$
\bar{W}_{-1 / 2+i \tau_{m}}\left(\alpha_{1}, \alpha_{3}\right)=0 \text {. }
$$

The potential distribution $U(\alpha, \beta)(3)$ written in the form of series in eigenfunctions (4) satisfies the homogeneous boundary conditions on the cathode and anode surfaces $U\left(\alpha_{1}, \beta\right)=0, U\left(\alpha_{3}, \beta\right)=0(\beta \in[0, \pi])$.

In order to fulfil the potential distribution continuity condition and to found the coefficients $A_{n}$ and $B_{m}$ in the expantions (4)-(6) the additional boundary conditions can be used:

$$
\begin{gathered}
U_{1}\left(\alpha_{2}, \beta\right)=U_{2}\left(\alpha_{2}, \beta\right)= \begin{cases}U_{3}\left(\alpha_{2}, \beta\right), & 0 \leqslant \beta<\beta_{0}, \\
f(\beta), & \beta<\beta_{0} \leqslant \pi,\end{cases} \\
U_{3}\left(\alpha, \beta_{0}\right)= \begin{cases}U_{1}\left(\alpha, \beta_{0}\right), & \alpha_{1} \leqslant \alpha \leqslant \alpha_{2}, \\
U_{2}\left(\alpha, \beta_{0}\right), & \alpha_{2} \leqslant \alpha \leqslant \alpha_{3} .\end{cases}
\end{gathered}
$$

Conditions (7) and (8) provide not only potential distribution continuity, but also the continuity of its first derivative due to the fact that the boundary points of subdomains (1), (2) at $\alpha=\alpha_{2}$ are internal points of subdomain (3) for $0 \leqslant \beta<\beta_{0}$, and that the boundary points of subdomain (3) at $\beta=\beta_{0}\left(\alpha_{1} \leqslant \alpha \leqslant \alpha_{3}\right)$ are internal points of subdomain (1) for $\alpha_{1} \leqslant \alpha \leqslant \alpha_{2}$ and subdomain (2) for $\alpha_{2} \leqslant \alpha \leqslant \alpha_{3}$.

Making use of formulas (1), (4), (7), (8) it turns out that

$$
\begin{gathered}
\sum_{n=0}^{\infty} A_{n} P_{n}(\cos \beta)= \begin{cases}\sum_{m=1}^{\infty} B_{m} \bar{W}_{-1 / 2+i \tau_{m}}\left(\alpha_{1}, \alpha_{2}\right) \frac{P_{-1 / 2+i \tau_{m}}(\cos \beta)}{P_{-1 / 2+i \tau_{m}}\left(\cos \beta_{0}\right)}, & 0 \leqslant \beta<\beta_{0},\end{cases} \\
\sum_{m=1}^{\infty} B_{m} \bar{W}_{-1 / 2+i \tau_{m}}\left(\alpha_{1}, \alpha\right)= \begin{cases}\sum_{n=0}^{\infty} A_{n} P_{n}\left(\cos \beta_{0}\right) \frac{W_{n}\left(\alpha_{1}, \alpha\right)}{W_{n}\left(\alpha_{1}, \alpha_{2}\right)}, & \alpha_{1} \leqslant \alpha \leqslant \alpha_{2}, \\
\sum_{n=0}^{\infty} A_{n} P_{n}\left(\cos \beta_{0}\right) \frac{W_{n}\left(\alpha, \alpha_{3}\right)}{W_{n}\left(\alpha_{2}, \alpha_{3}\right)}, & \alpha_{2} \leqslant \alpha \leqslant \alpha_{3} .\end{cases}
\end{gathered}
$$


The orthogonality of the eigenfunctions systems in the variables $\beta$ (9) and $\alpha$ (10) leads to the linear algebraic equations system

$$
\begin{gathered}
A_{n}-(n+1 / 2) \sum_{m=1}^{\infty} B_{m} \frac{\bar{W}_{-1 / 2+i \tau_{m}}\left(\alpha_{1}, \alpha_{2}\right)}{P_{-1 / 2+i \tau_{m}}\left(\cos \beta_{0}\right)} \times \\
\times \int_{0}^{\beta_{0}} \sin (\beta) P_{n}(\cos \beta) P_{-1 / 2+i \tau_{m}}(\cos \beta) d \beta= \\
=(n+1 / 2) \int_{\beta_{0}}^{\pi} \sin (\beta) P_{n}(\cos \beta) f(\beta) d \beta \\
\times\left[\frac{1}{W_{n}\left(\alpha_{1}, \alpha_{2}\right)} \int_{\alpha_{1}}^{\alpha_{2}} \sinh (\alpha) \bar{W}_{-1 / 2+i \tau_{m}}\left(\alpha_{1}, \alpha\right) W_{n}\left(\alpha_{1}, \alpha\right) d \alpha+\right. \\
\left.+\frac{1}{W_{n}\left(\alpha_{2}, \alpha_{3}\right)} \int_{\alpha_{2}}^{\alpha_{3}} \sinh (\alpha) \bar{W}_{-1 / 2+i \tau_{m}}^{\infty}\left(\alpha_{1}, \alpha\right) W_{n}\left(\alpha, \alpha_{3}\right) d \alpha\right]=0,
\end{gathered}
$$

where $N_{m}=\int_{\alpha_{1}}^{\alpha_{3}} \sinh \alpha\left(\bar{W}_{-1 / 2+i \tau_{m}}\left(\alpha_{1}, \alpha\right)\right)^{2} d \alpha$ - eigenfunction normalization constant.

4. Conclusion. This paper presents the mathematical model of the rotationally symmetrical field emission triode system on the base of field emitter with ellipsoid surface. The anode surface is an ellipsoid of revolution, the modulator surface is a part of an ellipsoid of revolution. To calculate the potential distribution, the boundary problem for the Laplace equation (1), (2) was solved by the separation variables method. The internal region of the emission system was divided into three overlapping subdomains. In each of the subdomains, the electrostatic potential distribution was presented in the form of series by the Legendre functions (3)-(6). Additional conditions (7), (8) ensuring the potential continuity and its first derivative made it possible to reduce the initial boundary problem to a system of linear equations (11), (12) relative to the unknown coefficients in the potential expansion (4). Thus, the potential distribution is found in the entire area of the field emission triode system.

\section{References}

1. Bachmann M., Dusberg F., Langer C., Herdl F., Bergbreiter L., Dams F., Miyakawa N., Eggert T., Pahlke A., Edler S., Prommesberger C., Lawrowski R., Hausladen M., Schreiner R. Vacuumsealed field emission electron gun. Journal of Vacuum Science and Technology B. Nanotechnology and Microelectronics, 2020, vol. 38, iss. 2, no. 023203.

2. Tripathi P., Gupta B. K., Bankar P. K., More M. A., Late D. J., Srivastava O. N. Graphene nanosheets assisted carbon hollow cylinder for high-performance field emission applications. Materials Research Express, 2019, vol. 6, iss. 9, no. 095066.

3. Jones W. M., Lukin D., Scherer A. Practical nanoscale field emission devices for integrated circuits. Applied Physics Letters, 2017, vol. 110, iss. 26, no. 263101. 
4. Sominskii G. G., Tumareva T. A., Taradaev E. P., Rukavitsyna A. A., Givargizov M. E., Stepanova A. N. Annular multi-tip field emitters with metal-fullerene protective coatings. Technical Physics, 2019, vol. 64, iss. 2, pp. 270-273.

5. Nguyen H. D., Kang J. S., Li M., Hu Y. High-performance field emission based on nanostructured tin selenide for nanoscale vacuum transistors. Nanoscale, 2019, vol. 11, iss. 7, pp. 3129-3137.

6. Vinogradova E. M., Egorov N. V., Televnyi D. S. Calculation of a triode field-emission system with a modulator. Technical Physics, 2014, vol. 59, iss. 2, pp. 291-296.

7. Egorov N. V., Vinogradova E. M. Mathematical modeling of the electron beam formatting systems on the basis of field emission cathodes with various shapes. User Modeling and User-Adapted Interaction, 2003, vol. 72, iss. 2, pp. 103-111.

8. Majić M. R. A., Gray F., Auguié B., Ru E. C. L. Electrostatic limit of the T-matrix for electromagnetic scattering: Exact results for spheroidal particles. Journal of Quantitative Spectroscopy and Radiative Transfer, 2017, vol. 200, pp. 50-58.

9. Majić M. R. A., Gray F., Auguié B., Ru E. C. L. Spheroidal harmonic expansions for the solution of Laplace's equation for a point source near a sphere. Physical Review E, 2017, vol. 95, iss. 3, no. 033307.

10. Techaumnat B., Huynh V., Hidaka K. Three-dimensional lectromechanical analysis of a conducting prolate spheroid on a grounded plane. IEEE Transactions on Dielectrics and Electrical Insulation, 2014, vol. 21, iss. 1, pp. 80-87, no. 6740728.

11. Xue C., Edmiston R., Deng S. Image theory for Neumann functions in the prolate spheroidal geometry. Advances in Mathematical Physics, 2018, vol. 2018, no. 7683929.

12. Abramowitz M., Stegun I. A. Handbook of mathematical functions with formulas, graphs, and mathematical tables. Washington, DC, NBS Press, 1964, 1046 p. (Applied Mathematics. Series 55).

13. Bateman H., Erdelyi A. Higher transcendental functions. In 2 vol. New York, Toronto, London, McGraw-Hill Book Company Inc., 1953, vol. 1, 302 p.

14. Gradshteyn I. S., Ryzhik I. M. Table of integrals, series, and products. 7th ed. Amsterdam, Boston, Heidelberg, London, New York, Oxford, Paris, San Diego, San Francisco, Singapore, Sydney, Tokyo, Academic Press, 2007, 1171 p.

Received: December 18, 2020.

Accepted: April 05, 2021.

Authors' information:

Nickolay V. Egorov - Dr. Sci. in Physics and Mathematics, Professor; robby7@mail.ru

Ekaterina M. Vinogradova - Dr. Sci. in Physics and Mathematics, Professor; e.m.vinogradova@spbu.ru

\title{
Математическое моделирование триодной системы на основе полевого катода эллипсоидальной формы*
}

\author{
H. В. Егоров, E. М. Виноградова
}

Санкт-Петербургский государственный университет, Российская Федерация, 199034, Санкт-Петербург, Университетская наб., 7-9

Для цитирования: Egorov N. V., Vinogradova E. M. Mathematical modeling of triode system on the basis of field emitter with ellipsoid shape // Вестник Санкт-Петербургского университета. Прикладная математика. Информатика. Процессы управления. 2021. Т. 17. Вып. 2. C. 131-136. https://doi.org/10.21638/11701/spbu10.2021.203

Данная статья посвящена математическому моделированию осесимметричной триодной эмиссионной системы на основе полевого эмиттера. Эмиттер представляет собой эллипсоид вращения, анод - конфокальную эллипсоидальную поверхность вращения, модулятор - часть эллипсоидальной поверхности вращения, конфокальной с поверхностями катода и анода. Граничная задача решена для уравнения Лапласа в вытяну-

* Работа выполнена при финансовой поддержке Российского фонда фундаментальных исследований (грант № 20-07-01086). 
тых сфероидальных координатах с граничными условиями первого рода. Для расчета распределения электростатического потенциала был использован метод разделения переменных. Распределение потенциала представлено в виде разложений по функциям Лежандра. Коэффициенты разложений являются решением системы линейных алгебраических уравнений. Все геометрические размеры системы являются параметрами задачи.

Ключевые слова: микро- и наноэлектроника, полевой эмиттер, полевая эмиссия, математическое моделирование, электростатический потенциал, граничная задача, функции Лежандра.

Контактная информация:

Егоров Николай Василъевич - д-р физ.-мат. наук, проф.; robby7@mail.ru

Виноградова Екатерина Михайловна - д-р физ.-мат. наук, проф.; e.m.vinogradova@spbu.ru 